\title{
UMA LEITURA ERÓTICA DE SÔSEKI ${ }^{1}$
}

\section{Madalena Natsuko Hashimoto Cordaro²}

Resumo: Pensar numa leitura das obras literárias de Sôseki que explore aspectos eróticos parece, num primeiro sentido, um contrasenso, já que em nenhum aspecto se revelam as punções claramente assim expressadas, ao contrário do que ocorre na escrita de seu contemporâneo Mori Ôgai (especialmente em Vita sexualis). De fato, a nova ordem social do período Meiji coloca no ostracismo as formas abertas dos relacionamentos da paixão que haviam sido até então sobejamente cultivados, seja no conceito de irogonomi do período Heian (794-1192), seja em sua retomada paródica como kôshoku centrada em Edo (1603-1878). A angústia da domesticação dos relacionamentos amorosos baseados numa monogamia impingida encontra-se no âmago de alguns protagonistas dos romances de Sôseki, e é sobre eles que se pretende refletir no presente estudo.

Palavras-chave: período Meiji; Natsume Sôseki; aspectos eróticos; análise de personagens; homoerotismo.

Abstract: To think on an interpretation of Sôseki's novels that explores erotic aspects would seem, in a first glance, a nonsense, as there are no real assurances that such revelations were clearly expressed, unlike what has happened in Mori Ôgai's writings (especially in Vita sexualis). As a matter of fact, Meiji period new social order has overshadowed the open ways of passion relationships that had been since then luxuriously cultivated, be it in the irogonomi concept of Heian period (794-1192), be it in its parodic return as kôshoku in Edo period (1603-1878). The domestication angst of love relations based upon an enforced monogamy is at the core of some Sôseki's novel protagonists, and is about them that we are aiming to reflect upon in this essay. Keywords: Meiji period; Natsume Sôseki; erotic aspects; character's analysis; homoerotism.

É fato que, em uma nova era, especialmente quando as transformações provocam ebulições notáveis e desestabilizam sistemas de valores e modos de vida, vocábulos que tentem expressar tais visões devam ser inventados, importados ou ressignificados. A movimentação linguística que se instaurou entre os pensadores, políticos, educadores,

1 O presente texto é resultante de reflexão apresentada no Simpósio "Natsume Sôseki: época, sociedade e obras literárias", evento em rememoração ao centenário do falecimento do escritor, organizado pelo Centro de Estudos Japoneses da USP e Aichi Prefectural University em outubro de 2016.

2 A autora é livre docente na área de Literatura e Arte Japonesa junto ao Departamento de Letras Orientais da Faculdade de Filosofia, Letras e Ciências Humanas da USP. 
escritores, homens e mulheres comuns no Japão do período Meiji tem sido foco de estudos não só na área de estudos históricos e sociais, mas também na das letras, e notadamente na seara da tradução: Futabatei Shimei 二葉亭四迷 (1864-1909) no russo, Mori Ôgai 森鷗外 (1862-1922) no alemão, Natsume Sôseki 夏目漱石 (1867-1916) no inglês. Modos de escrita japonesa que remontam ao elegante período clássico (wabun 和 文), níveis de oficialidade da expressão sinificante (kanbunkundoku 漢文訓読), busca de unificação da escrita nivelada a suposta fala unificada (genbun itchi 言文一致), invenção de novos conceitos e realizações sociais ocupam páginas de jornais e posições de intelectuais, escritores e educadores chegam a propostas tão variadas quanto à da supressão simples e completa dos ideogramas na língua japonesa.

Formado na recém-inaugurada área de língua inglesa da Universidade de Tóquio, na vaga do escritor greco-irlandês-americano Koizumi Yakumo 小泉八雲 (Lafcadio Hearn, 1850-1904), Natsume Sôseki certamente também foi muito sensível ao campo semântico das diferenças culturais expressas através da expressão oral, tendo sido responsável pela invenção de muitos vocábulos inéditos, alguns dos quais se restringiram somente a seu próprio uso, enquanto outros se tornaram parte integrante da língua moderna.

Muitos críticos analisam a obra de Sôseki sob o viés de sua representatividade em vista de uma nova mentalidade abraçada pela elite do período Meiji, que resultou em conflitos gerados pelo embate de uma moral confuciana (dita "feudal") e baseada na diferenciação de irremovíveis posição e nascimento contra pensamentos contemporâneos, e muitas vezes nem tanto, de um Ocidente compreendido como democrático, iluminado, racional e cristão. A modernidade japonesa se instaura numa nova ordem de igualdade social e igualmente tenta reformar os relacionamentos entre os homens e as mulheres. Não se toleram mais os samurais, dizem-se adeus aos daimios e a famílias estendidas no sistema iemoto, almejam-se cortar as raízes que os prendem a um passado ora fonte de profunda recusa e embaraço frente a éticas ocidentais. A intensificação do patriarcado dessa vez se concentra em famílias nucleares, onde a mulher mãe e esposa deve respeitar o ressignificado sistema centrado nas relações ie.

Debruçando-nos sobre o léxico amoroso, notamos que, como aponta Levy ${ }^{3}$, primeiramente o termo "amor" aparece como empréstimo linguístico do inglês ( $r a b u$ ou $r a ̂ b u)$, mas logo é traduzido para o japonês como ai 愛, ou ren'ai 恋愛, um conceito eminentemente cristão. Aponta a pesquisadora também a redução de um rico vocabulário do período Edo em relação a relações afetivas: iro 色, koi 恋, nasake 情 け, irogonomi 色好み, kôshoku 好色, shikidô色道 foram todos relacionados à luxúria (2011, p. 73), um dos terríveis sete pecados capitais. Poderíamos ainda acrescentar outros termos que grassavam nos escritos então tachados como vulgares e indignos mas que eram fartamente utilizados até há pouco em Edo, tornada Tóquio no período Meiji: wakashudo 若衆道 (o caminho de amar rapazes), nyodô 女道 (o caminho de amar mulheres), nanshoku 男色 (o apreço pelo amar homens), nyoshoku 女色 (o apreço pelo

3 LEVY, Indra (ed.). Translation in Modern Japan. Londres e Nova York: Routledge, 2011. 
amar mulheres), onnagirai 女嫌い (a repulsa a mulheres), tomogui 共食い (o devorar a companheira). Sofre grande golpe o universo das áreas de prazeres, as figuras de cortesãs de diversos ranques e preços, gueixas das artes mais sofisticadas, dançarinas de expressividade ímpar, garçonetes impertinentes, massagistas hábeis das casas de banho, músicos e guias expertos dos entretenimentos, atores jovens e maduros, atores onnagata, mulheres e rapazes sustentados e em efêmeros relacionamentos. Embora a áreas de prazeres Yoshiwara somente tenha sido fechada em 1956, sua posição após a Restauração Meiji foi quase que totalmente relegada ao ostracismo e ao anacronismo, uma presença dificilmente reconhecida pelo mundo da legalidade então empenhada em emular os modos civilizados de uma Inglaterra, de uma Alemanha. Diminui crescentemente em luxo e apelo sensual o esplendor da cortesã yûjo 遊女, dantes sinônimo de requinte artístico na dança, no arranjo floral, na cerimônia de chá e de aromas, na caligrafia e no desenho, que em geral costumava se agregar a alguma grande casa após servido o termo de dez anos em algum estabelecimento. Cortesãs representadas como a bodisatva da misericórdia Kannon, como se veem nas pinturas de Hishikawa Moronobu 菱川 師宣 (1618?-1694) e nos escritos de Ihara Saikaku 井原西鶴 (1642-1693), atestam a proximidade à sacralidade que o corpo sensual tinha, em conexão direta com o papel executado desde a antiguidade pelas miko em sua ligação física com as divindades. $\mathrm{O}$ estigma cristão recém importado engloba as trabalhadoras do mundo dos sentidos na posição única de "prostituta" e as relegam à marginalidade para o restante de suas vidas. O decreto de 1872 promulgado pelo governo de Meiji é eloquente: "Prostitutas e gueixas perdem seus direitos humanos, tornando-se iguais a cavalos e gado". Embora a monogamia passe a ser o sistema oficial para as relações amorosas, para os homens as relações extra-maritais são toleradas, o que ainda proporciona uma sobre-vida às profissionais dos sentidos.

Os dramas de Chikamatsu e de todo um filão de enredos de teatro kabuki e narrativas populares, com triângulos, quadriláteros ou mosaicos amorosos em ligações efêmeras vividos por esposas, cortesãs e ocasionais amantes não mais possuem relevância no Japão do período Meiji e desaparecem quase completamente dos escritos literários. Registrem-se exceções: Mori Ôgai 森鷗外 (1862-1922), Tayama Katai 田山 花袋 (1871-1930), entre outros, e um notável ponto de vista feminino de Higuchi Ichiyô 樋口一葉 (1872-1896) e outro, posterior, de Hayashi Fumiko 林芙美子 (1903-1951).

Saeki ${ }^{5}$, em seu ensaio sobre a passagem do conceito de iro 色 enquanto sinônimo de luxúria e $a i$ 愛, de amor desinteressado, parte da conceituação de Tsubouchi Shôyô 坪内逍遥 (1859-1935), que defende a “emoção" (ninjô 人情) como elemento principal do romance, e categoriza, juntamente com seus contemporâneos, os assuntos do iro 色 (eros, paixão, desejo) em três níveis: o mais baixo, centrado no desejo típico de pássaros

4 Análise de Ishii Kendô, Meiji jinbutsu kigen (Shun’yôdô, 1926), p. 41, apud Saeki, pp. 83-84.

5 SAEKI, Junko. "From iro (eros) to ai=love: the case of Tsubouchi Shôyô". Trad. Indra Levy. In LEVY, Indra, op. cit., pp. 73-101. 
e animais; o intermediário, autocentrado em relação à adoração do outro; e o superior, originado da admiração e do respeito mútuo. É este koi 恋 superior que se focaria na interioridade. Conforme aponta Saeki, na contemporaneidade:

A palavra iro 色, que em seu sentido mais amplo poderia ser traduzido como "eros", é limitada aos seus sentidos estritos de "desejo físico" e "beleza física", enquanto que as palavras $a i$ 愛e ren 'ai 恋愛 são evocadas para expressar sua relação diamentralmente oposta, a esfera espiritual. (op. cit., p. 76)

Tal dicotomia, notamos, inexiste nos escritos anteriores ao período Meiji. Saeki lembra, ainda, a ressignificação do termo ai 愛, que no léxico budista significava "obsessão", ou "cobiça", uma conotação negativa de ligações mundanas, mas que foi a eleita para ser utilizada na tradução da Bíblia como "o amor de Deus", tendo sido a partir de então sacralizada (2011, p. 80). Pesquisando dicionários etimológicos, vemos que tal acepção budista corresponde a seu sétimo sentido, cronologicamente aparecido. Em primeiro, registra-se coração em harmonia entre pais, filhos e irmãos e, por associação, entre homens e entes viventes (exemplificado por poema da coletânea Man'yôsh û 『万葉集』, 20 vols. compilados em 759). Em segundo, sinônimo de $k o i$ 恋, o sentimento de desejo do outro, na relação homem e mulher. Em terceiro, o sentimento de cuidar de outrem, de mimar o outro (exemplificado por passagem na obra Otogizôshi 『御伽草子』, compilada entre 1716 e 1736). Em quarto, apreciar, gostar, amar, elogiar (exemplificado por passagem na coletânea Seisuishô 『醒睡笑』, coletânea em 8 volumes de contos cômicos, compilada em 1623). Em quinto, como aparece na obra de Saikaku, Kôshoku nidai otoko『好色二代男』 (Segundo Homem que Se Deu ao Amor), o sentido utilizado é o de ter aparência atraente e charmosa, aikyô 愛敬. Finalmente, o sexto sentido é budista lembrado por Saeki, e o sétimo, o utilizado na tradução da bíblia cristã. E, curiosamente, em oitavo, o ideograma aparece como abreviatura de Irlanda (Airan 愛蘭). ${ }^{6}$

Impossível pensar em escolher esposas num tempo de organização coletivista (e não se olvidem os relacionamentos expressos nas obras do período da corte de Heian, quando todas as mulheres são objetos possíveis do Imperador), como lembram muitos pesquisadores. Murakami ${ }^{7}$ lembra, após analisar obras de Ozaki Kôyô 尾崎紅葉 (18671903) e Futabatei Shimei 二葉亭四迷 (1864-1909): “Se amantes são representados como imagens de amigos ou parentes nas obras da literatura de Meiji, esse modo de descrição é motivado pela propensão a suprimir eros, inata à dicotomia cristã" (1991, p. 230). Lembra Murakami ainda que "para os heróis de um ninjô-bon, dirigirem-se a um

6 Consulta no dicionário eletrônico Kôjien.

7 MURAKAMI, Takayuki. "Lovers in Disguise: A Feature of Romantic Love in Meiji Literature". In Comparative Literature Studies, Vol. 28, No. 3, 1991, pp.213-233. Penn State University Press. http://www.jstor.org/stable/40246789. 
amante como um amigo seria simplesmente ridículo, enquanto na literatura ocidental o amor heterosexual é geralmente apresentado no nível da amizade.” (p. 224).

Karatani $^{8}$, em estudo visceral sobre as origens da literatura moderna japonesa, também lembra que antes do período Meiji o que ocorria era "a inexistência do amor romântico (ren'ai 恋愛), havendo apenas a sensibilidade de iki 粋 ou elegância”, e enfatiza que "a noção de amor romântico começou a ser difundido na sociedade japonesa pelas igrejas cristãs, tanto que é difícil discernir se os jovens que lá se reuniam assim o faziam por causa de uma preocupação pela fé ou por romance."

Quando examinamos a questão de um tipo de relacionamento anterior ao período Meiji no qual se poderia conotar o amor romântico, vem-nos à mente o conto "Kikuka-no chigiri”「㐘花の約」(“O pacto do crisântemo”), de Ueda Akinari 上田秋成 (17341809): a lealdade de um companheiro que abraça a morte enquanto insignificância frente ao cumprimento de um juramento solene entre os amantes, em relação de mais velho (ani-bun 兄分) e mais novo (otôto-bun 弟分). Atente-se que os parceiros de tal amor elevado são ambos do mesmo sexo (dôsei 同性 também será um neologismo do período Meiji utilizado por Sôseki) e seu compromisso é selado na lealdade do mais novo ao que lhe é anterior, com cúmplice anuência de sua mãe.

Se, por um lado, para os ocidentais de fins do século XIX o encontro com imagens eróticas shunga 春画 e organizações reais dedicadas aos deleitos dos prazeres físicos foi um grande choque, é de se supor que, por outro, o mesmo tenha ocorrido com um Japão que tentava se conformar a uma nova ordem de tratamento de igualdade social e de gênero. A pintura de Kuroda Seiki 黒田清輝 (1866-1924) bem mostra como, por influência de uma nova figuração ocidental, o nu se impõe como motivo e adquire uma transcendência simbólica, a ponto de significar Sabedoria, Impressão e Sentimento ( 智 - 感 - 情, obra de 1899-1900).

Lembremos novamente de uma análise perspicaz de Karatani:

Longe de ser natural, o amor romântico foi para eles um tipo de febre religiosa. Essa febre foi comunicada pela literatura até para aqueles que não haviam tido contato direto com o cristianismo. As pessoas se tornaram obssecadas por um problema estranho que era chamado ai愛, não koi恋. Até Sôseki, que não apreciava o cristianismo, se entranhou no problema de ai em suas tentativas de lidar com amor.

Reconhecendo, entretanto, que intelectuais como Nishida Kitarô ou o próprio Natsume Sôseki buscaram a transcendência do sofrimento através do zenbudismo e cultivaram um espírito mais livre de suas amarras de época, Karatani conclui

8 KARATANI Kojin. Origins of Modern Japanese Literature. Trad. Brett de Bary. Durham e Londres: Duke University Press, 1993. Versão Kindle 44\% Pos. 2077 de 4693.

9 Idem, ibidem. 
que a concepção cristã abraçada nos anos de 1890 e inícios de 1900 acabou por desembocar no naturalismo, movimento literário no qual a carne e o desejo sexual foram "produzidos pela repressão do corpo"10, numa absorção, diríamos, bastante complexa das fontes ocidentais, âmbito do qual a literatura brasileira também não conseguiu se alienar. Tal repressão erótica coloca na marginalidade a liberalidade das relações amorosas que se via em Edo, e os temas amorosos envolvendo competições, traições, adultério e desvios do amor heterosexual casto se tornam motivos geradores de sentimentos de grande culpa, delito e crime perpretados nos protagonistas, sendo então reprimidos às raias da indizibilidade. Ainda décadas mais tarde, em obras Kawabata Yasunari 川端康成 (1899-1972) é perceptível o grande sentimento de culpa (tsumi 罪) resultado por relações amorosas que extrapolam as amarras do casamento monogâmico, como se elas próprias fossem por si mesmas grande fonte de pecado.

A obra de Sôseki tem sido analisada sob múltiplos prismas, é claro - apenas o tema de sua recepção no Japão e no estrangeiro ocuparia por si só volumes copiosos -, mas o que parece ser uma proposição estranha, abordar a expressão erótica, tem encontrado eco predominante em abordagens mais recentes. Em estudo de Keith Vincent encontramos uma aproximação psicanalítica ${ }^{11}$. Mas, antes, dignos de nota foram as reflexões do psicólogo japonês Doi Takeo 土井健郎 (1920-2009) ${ }^{12}$, das quais destacaremos algumas relativas às pulsões eróticas ocultas nas entrelinhas das ações de alguns de seus protagonistas. Botchan (Botchan 坊っちゃん: Botchan, 1906) expressa seu desejo de ser amado através da dependência (amae 甘え) de sua ama Kiyo, um relacionamento erotizado ao extremo. Sanshirōô (Sanshirô 三四郎: Sanshiro, 1908) confronta a tarefa central da adolescência: relacionar-se com o sexo oposto, qual ovelha desgarrada e abandonada ("Pity's akin to love" é frase expressada em inglês no romance). O neurótico Daisuke (Sorekara それか ら: E Depois, 1909) revela tendências homosexuais latentes em relação a Hiraoka e seu olhar de triunfo quando o amigo arrebata Michiyo e, mesmo quando se decide por amála, tê-lo-ia feito mais para se vingar do antigo amigo. Podemos lembrar como Daisuke é descrito por Sôseki em sua apresentação, quando se arruma "exatamente como uma mulher": um dândi, um bonvivant, um apreciador das artes e das gueixas, mas sem nunca com elas se envolver, aproximando-se da representação de uma figura assexuada. Sôsuke (Mon 門: O Portal, 1910), privilegiado estudante universitário, comete uma "indiscrição" em relação a Oyone, então casada com seu amigo Yasui, e deve fugir com ela e levar uma vida cada vez mais deteriorada. Doi analisa: "podemos dizer que a relação entre os dois

10 Idem, ibidem. Kindle 46\% Pos. 2191 de 4693.

11 VINCENT, Keith J. "Sexuality and narrative in Sôseki's Kokoro". In CORNYETZ, Nina; KEITH VINCENT, J. (eds.). Perversion and Modern Japan - Psychoanalysis, literature, culture. New York: Routledge, 2011.

12 DOI, Takeo; TYLER, William J. The Psychological World of Natsume Sôseki. Cambridge: Harvard University, 1976. 
homens (Sôsuke e Yasui) era provavelmente de um latente homossexualismo e que existia uma coloração fortemente edipiana na amizade de Sôsuke com Oyone. Sensei (Kokoro こころ: Coração, 1914) vê o ardor entusiasmado do jovem como tendo se originado em sentimentos de solidão e frustação, ou um tipo de sentimento homosexual; a proposta de casamento de Sensei teria sido derivada por sentimentos homossexuais; Sensei prefere ter seu suicídio entendido como um sacrifício à passagem de uma era do que como lealdade originada por sentimentos homossexuais por $\mathrm{K}^{13}$

Chama a atenção a detecção de pulsões homoeróticas na análise de Doi, que não deixa de ser fascinante. Considerando-se que a sociedade de Edo compreendia os relacionamentos entre os homens como um dos caminhos do amor, de fato o mais belo, e que as mulheres de fato lhes eram em muito inferiores, lemos os romances de Sôseki atentando para uma presença muito tênue das personagens femininas, pouco desenvolvidas psicologicamente (na verdade, o mesmo se pode afirmar para grande parte dos romances japoneses modernos). É verdade que elas apresentam novas facetas e funções, ainda que se conformem como sombras efêmeras coadjuvantes dos protagonistas. Afastadas nos estudos a uma posição de subalternidade (as escolas femininas estabelecidas em 1872 ensinavam corte e costura, prendas do lar, línguas japonesa e inglesa dos 8 aos 15 anos somente) e das posições de destaque social, restritas no período Meiji quase que totalmente ao âmbito do lar Segundo a égide da “boa esposa, mãe sábia” (ryôsai kenbo 良妻賢母), as personagens femininas de Sôseki pouco têm a dizer sobre o mundo, ou mesmo sobre seus sentimentos em relação aos parceiros amorosos, sendo recipientes das iniciativas dos mais poderosos. As gueixas anteriores diziam de si muito mais, ainda que mentissem, sendo seus papeis claramente delimitados nas fronteiras do estimular desejos.

A coexistência de caminhos do amor entre garotos encontra-se bem representada na obra Vita sexualis de Mori Ôgai, na qual, entretanto, nota-se que ocorre uma restrição à fase dos estudos básicos: na vida adulta, os meninos do grupo kôha 硬派 (os durões, de estrato samurai, especialmente de Kagoshima) deixam seus companheiros de bravatas diurnas e noturnas e se tornam mais como os nanpa 軟派, conformando-se com se relacionarem somente com o sexo oposto ${ }^{14}$. Pelo menos no mundo da oficialidade, as relações heterossexuais se manterão na idade adulta como as únicas aceitáveis. A

13 Como se nota pela acurácia da análise psicológica de Doi, a escrita de Sôseki só faz comprovar sua reputação enquanto praticante de uma criação de personagens de rica individualidade e interioridade, características intrínsecas do período moderno em que se insere. Personagens se confundem com pessoas.

14 Na obra de Ôgai, entre os adolescentes internos dos colégios, o grupo dos kôha englobaria principalmente os oriundos de Kagoshima, brutos e broncos, a quem apraz executar ações violentas e, à noite, buscar a companhia sorrateira de colegas nos leitos, sendo totalmente ineptos nas relações com as meninas. Já os do grupo nanpa seriam mais sensíveis aos bons modos, itens de vestuário e delicadezas que agradam as moças das casas de banho, com elas se relacionando livremente, sendo por isso desprezados pelos colegas. Passada a fase escolar, todos se tornariam heterossexuais, com casamentos e posições sociais rigidamente hierarquizadas. 
existência de uma produção francamente erótica na literatura e na pintura é referida na referida obra de Ôgai, no personagem ainda menino que descobre as "estampas do travesseiro" (makura-e 枕絵) sendo observadas por duas vizinhas. Mas não parecem ter sido registradas por Sôseki, salvo engano. Sanshirô, mesmo dividindo um leito com uma mulher mais velha, não ousa mover um único músculo, completamente paralisado, auferindo a reputação de "covarde" pela companheira, que certamente esperava mais ação, talvez um fugaz momento de olvido erótico. Daisuke passa algumas noites em elegantes aposentos de prazeres, mas assepticamente enlevado por dança, música, conversação e quitutes líquidos e sólidos. É de se supor que, assim como em Genji monogatari não se expressam claramente descrições de intercursos amorosos como o fizeram prolificamente os pintores e escritores do período Edo, talvez Sôseki tenha se utilizado da mesma névoa enunciadora, posicionando estratégicos silêncios que fazem seus leitores se questionarem ainda hoje.

Embora alguns críticos até cheguem a defender que Kokoro seja uma obraprima de romance homossexual, concordamos com Vincent, que a interpreta como uma obra que "coloca em diálogo duas concepções de sexualidade como pontos opostos em uma narrativa e que reconhece o papel mesmo da narrativa no modo como a sexualidade é experenciada e compreendida" (2010, p. 223). Prova-se ser inerente na obra de Sôseki, nesse sentido, uma concepção na qual se nota uma continuação do conceito dos "caminhos do amor" (shikidô色道) como praticado no período Edo, dessa vez eufemisticamente preteridos pela predominância do exclusivo amor heterosexual.

Assim como no início do período Meiji, a tradução, hoje, das obras de Sôseki, deve ser estudada tendo em vista seu distanciamento semântico. A seguir, pretende-se, seguindo Vincent, analisar um trecho fulcral de Kokoro, levando-se em consideração suas considerações e acrescentando outras, além de justapor o texto original em japonês, a primeira tradução para o inglês de McClellan, de 1957, a do próprio Tyler quando houver, e a do português realizada no Brasil por Ota ${ }^{15}$.

Sensei e Watakushi caminham no Parque de Ueno na estação das flores, um motivo modelar para uma pintura ukiyo-e, ainda hoje prevalecente como figura bonita, lugar famoso e atividade sazonal das mais apreciadas. (E também para refúgio dos contemporâneos homeless que montam suas barracas às sombras.)

O termo koi恋, sobre o qual discutimos anteriormente, é traduzido por: "love", "paixão" e "falling in love", uma relação intransitiva, uma inclinação flutuante sem objeto fixo:

"Your heart has been made restless by love for quite some time now." (Trad. McClellan, apud Vincent, p. 222; Kindle 11\%)

15 Kokoro Coração. Trad. Junko Ota. São Paulo: Globo, 2008. 


\section{「（。。。）あなたの心はとっくの昔からすでに恋で動いているじやあ りませんか」}

- (...) Não é que seu coração funciona com paixão há muito tempo? (Trad. Ota, p. 54)

"Your heart has been stirred by the vision of falling in love for some time now." (Tyler, 1976, p.109)

O "coração" (heart) está bem expresso pelo escritor, e também nas traduções. Entretanto, a seguir, notamos diferenças entre elas: McClellan esclarece a expressão abertament, enquanto Ota utiliza novamente o termo "coração", em vez de "dentro do peito": "Dentro do meu peito, não existe nada que se possa dizer ser alvo de amor". O sentimento é vago, não direcionado a nenhum objeto em particular:

"But there is no one whom you might call the object of my love," I said. "I have not hidden anything from you, Sensei." (Trad. McClellan, apud Vincent, p. 222/ kindle $11 \%$ )

\section{「私の胸の中にこれという目的ものは一つもありません。私は先生に何 も隠してはいないつもりです」}

- Não tenho nada em meu coração. E não estou escondendo nada do senhor. (Trad. Ota, p. 54)

Como analisa Vincent (p. 227), a sexualidade sem objeto é primeiramente dirigida a outro homem, mas no fim repousará em uma mulher. Essa ideia de pulsão erótica, inicialmente sem fixação em corpo ou espírito determinados, tem uma semelhança bastante notável nas atividades pueris descritas por Ôgai em seu Vita sexualis, se bem que este a coloque de um modo bem mais explícito. Lembramos também que, nas representações shunga do período Edo, crianças e efebos são tanto objetos quanto perpretadores de atos sensuais ou eróticos. O protagonista ainda menino de Saikaku já considera um ato sensual uma simples troca de cartas, uma visita noturna à casa de banho de mãos dadas com sua babá. E o mesmo se pode dizer de Genji, que antevê na menina Murasaki uma fonte de satisfação enquanto companhia de brincadeiras infantis e outras nem tanto. $\mathrm{O}$ teor didático que caracteriza a relação entre mestre e discípulo também se faz sentir notadamente nas atividades do coração, e certamente há um componente erótico nas relações dos pares numa sociedade predominantemente masculina. 
Enquanto a movimentação erótica (iroke 色気 é o termo utilizado por Sôseki) não se aquietar, a busca pela satisfação persistirá, e é assim que Sensei a compreende no jovem Watakushi:

"You are restless because your love has no object. If you could fall in love with some particular person, you wouldn't be so restless." (Trad. McClellan, apud Vincent, p. 222)

"But I am not so restless now." (Trad. McClellan, apud Vincent, p. 222/ kindle 11\%)

「目的ものがないから動くものです。あれば落ち付けるだろうと思って 動きたくなるのです」

「今それほじ動いちやいません」

- Ele se move porque está vazio. Ele quer se mover porque, se encontrar algo, pensa que acalmará. (Trad. Ota, p. 54)

- Nem se move tanto assim. (Trad. Ota, p. 55)

A movimentação, a inquietude está presente não por estar vazio, mas por não ter “algo/ alguém que seja o alvo" do amor koi 恋, paixão/ amor. Entretanto, na língua japonesa, não é Watakushi o indivíduo agente: é seu coração que quer se mover, que pensa, que se move afinal. Mas, é claro, trata-se do coração de Watakushi.

A parcimônia na utilização dos pronomes de tratamento, no caso japonês, continua sendo das mais complexas. Tão banal para nossos dias, o simples direcionamento em segundo pessoa através de um pronome direto mostra quão profundas haviam sido as reformas linguísticas pelos movimentos de modernização no período Meiji, como se nota no diálogo que se segue:

"Did you not come to me because you felt there was something lacking?"

"Yes. But me going to you was not the same thing as wanting to fall in love."

(Trad. McClellan, apud Vincent, p. 222/ kindle 11\%)

「あなたは物足りない結果私の所に動いて来たじやありませんか」

「それはそうかも知れません。しかしそれは恋とは違います。」 
- Você não veio movendo-se em minha direção, por insatisfação?

- Isso pode ser verdade. Mas é diferente da paixão. (Trad. Ota, p. 55)

A consciência de “faltar algo" (物足りない) talvez resulte em “insatisfação”, mas somente se tornará seu sinônimo quando deliberadamente se buscar sua completude, que foi, no caso de Watakushi, a sua aproximação a Sensei.

E é justamente assim compreendido:

"It was a step in your life toward love. The friendship that you sought in me is in reality a preparation for the love that you will seek in a woman." (Trad. McClellan, apud Vincent, p. 222/ kindle 11\%)

「恋に上る楷段なんです。異性と抱き合う順序として、まず同性の私の 所へ動いて来たのです」

- É um degrau para subir à paixão. Por uma questão de ordem, veio em primeiro lugar para mim, do mesmo sexo, para chegar depois a abraçar alguém do sexo oposto. (Trad. Ota, p. 55)

"They are a step in your life toward love... As a step toward embracing the opposite sex, you come to me, a member of your own sex.” (Trad. Tyler, 1978, p. 109)

"It's a staircase on the way to erotic love. You gravitated towards me, a member of your own sex, on your way to embracing the opposite sex." (Trad. Vincent, p. 229)

A questão que nos interessa, nesse trecho, é a oposição "mesmo sexo" (同性), “sexo oposto" (異性), neologismos registrado em 1876. McClellan limita a relação entre os dois homens enquanto amizade e preparação para o amor, necessariamente dirigido a uma mulher. Entretanto, no texto original, ambos são degraus do mesmo amor erótico koi 恋. Certamente, entretanto, trata-se de uma imagem na qual fica clara a superioridade do amor entre homem e mulher, pois é um degrau acima ao do entre iguais, se se escolher subi-lo. Watakushi ainda não tem ciência disso, ou, por viver no período Meiji, não pode ter conhecimento de práticas passadas que são para sua geração denegridas.

"I think that the two things are totally different."

"No, they are not. But being the kind of man that I am, I cannot help you to rid your 
heart of that feeling of want. Moreover, peculiar circumstances have made me even more useless than I might have been as a friend. (...)" (Trad. McClellan; Kindle 11\%)

\section{「私には二つのものが全く性質を異にしているように思われます」 \\ 「いや同じです。私は男としてどうしてもあなたに満足を与えられない 人間なのです。それから、ある特別の事情があって、なおさらあなたに 満足を与えられないでいるのです。（。。。）」}

- Acho que as duas coisas são de naturezas completamente distintas.

- Não, são a mesma coisa. Eu, por ser homem, jamais poderei satisfazer você. E ainda, por causa de um motivo particular, consigo menos ainda satisfazer você. (...) (Trad. Ota, p. 55)

Se, então, as duas coisas, abraçar um homem ou uma mulher, são a mesma coisa, como ensina Sensei ao aprendiz, poder-se-ia supor que ambos os caminhos poderiam ser válidos. McClellan traduz como "o tipo de homem que sou" e não simplesmente "enquanto homem", o que retira em muito a nuance homoerótica. Como veremos mais tarde, na obra de Mishima Yukio 三島由紀夫 (1925-1970), em especial em Confissões de uma Máscara (Kamen no kokuhaku『仮面の告白』, 1949) e Cores Proibidas (Kinjiki『禁色』, 1951-1953), nas quais o termo utilizado é justamente nanshoku 男 色, o homoerotismo ficou banido e completamente marginalizado a partir de então, embora famosas tenham permanecido ainda vigentes as práticas sexuais entre a gente ligada ao mundo dos entretenimentos sensuais.

Voltando, então, às apreciações de Vincent, notamos que Sôseki é referendado em relação às teorias de seu também contemporâneo austríaco Sigmund Freud (1856-1939):

"Para Sôseki, a narrativização da sexualidade enquanto desenvolvimento foi inseraparável das narrativas da ordem imperial global à qual ele se manteve crítico por toda sua carreira. (...) Freud (...) em Três Ensaios sobre a Teoria da Sexualidade dirige-a inequivocamente em direção à heterossexualidade genital. $\mathrm{O}$ argumento de Freud é uma modernização ao mesmo tempo em que defende uma trajetória única de progresso e diminui o papel da violência e repúdio que alimentam esse mesmo progresso. Para Sôseki, um escritor japonês que foi agudamente consciente de sua posicão na periferia global e enquanto súdito do Império Japonês, não havia possibilidade de ignorar que os que haviam alcançado o 'próximo estágio' o haviam feito pisoteando as costas de outros para chutá-los na face e, assim, não serem sobrepujados.” (p. 231) 
Como conclui Vincent, "Watakushi vai passar do estágio de 'perversão polimorfa', onde o objetivo sexual não tem nenhum objeto, para o amor com um membro de seu próprio sexo, e finalmente para o amor por uma mulher. Com esse alcance da heterossexualidade genital, Sensei conclui sua extraordinária narrativa freudiana de desenvolvimento sexual." (p. 227)

Se acompanhamos os escritos de Edo, vemos também que a fase homoerótica é mantida enquanto fisicalidade até certa idade; o jovenzinho deve ser eterno. Passados os anos verdes, dois companheiros podem sair em Peregrinação a Pé pela Tôkaidô (Tôkai dôchû hiza kurige 東海道中膝栗毛), como nos narra em 1802 Jippensha Ikku 十返舎一 九 (1756-1831), mas não mais enquanto par amoroso. Ou, como tratou o diretor Ôshima Nagisa 大島渚 (1932-2013) no filme Gohatto 御法度 (Tabu, ou Édito Xogunal), em 1999, enquanto narrative centrada no violento, vingativo e erótico jovenzinho em meio a guerreiros do grupo shinsengumi de fins de xogunato. O período bakumatsu 幕末, de decadência e desmoronamento da organização Tokugawa, caracterizou-se por gerar uma produção visual e literária marcada por forte violência, sexualidade, sangue, morte por assassinato e reviravoltas de enredo, muito notável no enredo, escrito pelo próprio Ôshima, e também na primeira fase da obra de Tanizaki Jun'ichirô 谷崎潤一郎 (1886-1965), também apodada “decadente”. Em 1916, ano do falecimento de Sôseki, Tanizaki tinha trinta anos, já tinha auferido elogios de Tayama Katai por seus contos Shisei 刺青 (Tatuagem, 1910), Himitsu 秘密 (O Segredo, 1911), Akuma 悪魔 (O Demônio, 1912); seus títulos já mostram a distância entre eles.

Como nos lembra Karatani, mesmo Sôseki não consegue escapar de certo conteúdo cristão, visível a nós pela distância do tempo. A maçã para sempre retorna a instilar o sentimento inexorável da culpa.

\section{「（...）とにかく恋は罪悪ですよ、よござんすか。そうして神聖なもの ですよ。」 \\ “(...) De qualquer forma, a paixão é delito, sabe? E também é divina.” (Trad. Ota, p. 56)}

A melancolia, solidão e nostalgia que parecem instigar Watakushi em direção a Sensei, então, levará a um sentimento da culpa divinizada. Se tal sentimento é o que faz Sensei alienar de sua afeição e confiança a sua esposa, não se pode afirmar com certeza. Justamente o distanciamento entre o casal confirma pontos de vista que interpretam o romance como sendo um hino ao amor homoerótico. Mas atenta o psicólogo Doi anteriormente referido que alguns até terminam a obra com capítulos nos quais Watakushi alegremente desposaria a viúva de Sensei.

Fosse tão simples a narrativa de Sôseki, não estaríamos a debatê-la ainda um século depois. Hoje, com a liberalidade que os movimentos de gênero têm conquistado no mundo ocidental e pró-ocidente, estudos enfocando o período Edo aumentam, e interpretações de escritores posteriores são revisitadas. É como enfoca Vincent: 
“(...) enquanto Watakushi se empenha em contar a história de como ele cresceu e se tornou um bom heterosexual, Kokoro de Sôseki sobrevoa sua mente para nos dizer que esse amadurecimento é um produto de uma narrativa motivada ao invés de ser uma questão de desenvolvimento natural. A obra nos mostra, em outras palavras, como Watakushi afirma ou encena seu próprio amadurecimento através de uma projeção de 'homossexualidade' em seu próprio passado, e no Sensei.” (p. 228)

Para uma leitura psicanalítica que tente encontrar rastros de repressão e símbolos elípticos, o seguinte trecho parece-nos ser modelar:

\begin{abstract}
- A lembrança de ter se ajoelhado algum dia diante de alguém faz com que se queira mais tarde pôr os pés na cabeça desse alguém. Para não ser humilhado amanhã, gostaria de eliminar o respeito de hoje. Em vez de suportar a solidão ainda maior no futuro, gostaria de suportar a solidão presente. Nos dias de hoje, repletos de liberdade, independência e egoísmo, temos todos que sentir essa solidão como sacrifício. (trad. Ota, p. 58)
\end{abstract}

Descontextualizados da narrativa, o trecho ainda assim coloca a violência da pressão social exercida sobre uma relação de doação de um alguém para outrem, fonte de humilhação social.

No período Edo, na literatura e arte que querem louvar o amor entre os de mesma marca sexualmente física, notamos que a predominância homem-menino é maior do que mulher-mulher. Estudos têm chamado a atenção para o ponto de vista predominante, que seria o "masculino", de suas representações eróticas. A crueza das descrições, como nos parece após termos passado por um processo romântico (ou religioso) de metáforas adocicadas, nos faz julgar como vulgares aspectos antes tidos como naturais. É assim que, quando Watakushi deve executar uma limpeza no ânus de seu pai, e justo nesse momento, foge e pega o trem para se encontrar com um Sensei já morto, e, no dizer de Vincent: "o fim já está enterrado no meio do romance, no instante mesmo das mortes dos dois pais e está suspenso entre a passividade e a ação." (p. 235)

Vincent utiliza a dicotomia entre passividade e atividade, como se as relações amorosas fossem unívocas, não importando a composição dos parceiros. Como se vê nas estampas e narrativas, a ambiguidade yin-yang é dinâmica e provoca curto-circuitos que fazem os elementos da equação nunca encontrar um equilíbrio. A premissa de Watakushi já parte de um falso silogismo.

E permanence um enigma: quem era o estrangeiro que acompanhava Sensei na praia logo na abertura do romance? Responsável sobretudo por chamar a atenção de Watakushi para Sensei, a isca desaparece e nenhuma menção se lhe faz. A escrita de Sôseki metonimicamente derrama pistas em passagens inesperadas que, em segundas ou terceiras leituras, acabam por conduzir o leitor a questionamentos que revelam as complexas ligações entre a vida política no mundo exterior e os personagens que perscruta em interioridades nada inocentes. Sobretudo, 
um estudo que perscrute em seus escritos a presença da guerra e do militarismo japonês seria muito pertinente.

A linguagem elíptica que formulou deixou impressão vívida em Akutagawa Ryûnosuke 芥川龍之介 (1892-1927), e podemos entrever a profunda repercussão de seu novo modo de escrever e interpretar as transformações de seu tempo, em um trecho de seu angustiante testamento literário, A vida de um idiota (Aru ahô no isshô 或阿朵 の一生):

10. O mestre

Lia um livro do mestre à sombra de um grande carvalho. Sob a luz do sol de outono, nenhuma folha sequer se movia. Em algum lugar, no espaço longínquo, uma balança, com pratos de vidro pendurados, mantinha um equilíbrio exato. Tal era a imagem que ele via enquanto lia o livro do mestre... ${ }^{16}$

Akutagawa morreu onze anos depois de seu Sensei, por ingestão de Veronal 0,8. Um ano antes, iniciava-se o período Shôwa e muitos eventos terríveis ainda estavam por vir. Ambos têm suas lápides no cemitério Zôjigaoka, em Tóquio.

\section{Bibliografia}

DOI, Takeo; TYLER, William J. The Psychological World of Natsume Sôseki. Cambridge: Harvard University, 1976.

HIRAKAWA, Sukehiro (ed.). Sôseki no “Kokoro": dô yomu ka, dô yomaretekita ka 漱石の 『こころ』どう読むか、どう読まれてきたか (“Kokoro” de Sôseki: Como ler? Como foi lido?). Tokyo: Shinyosha, 1992.

KARATANI Kojin. Origins of Modern Japanese Literature. Trad. Brett de Bary. Durham e Londres: Duke University Press, 1993.

MIYASAKI, Kasumi. "Valorizing Samurai Masculinity through Biblical Language: Christianity, Oscar Wilde and Sôseki's Novel Kokoro". In ARNOLD, J; BRADY, S. (eds.). What is Masculinity? Historical Dynamics from Antiquity to the Contemporary. Londres: Palgrave Macmillan, 2011.

McClELLAN, Edwin. "The Implications of Soseki's Kokoro". Monumenta Nipponica. Vol. 14, No. 3/4. (Out. 1958 - Jan. 1959), pp. 356-370. Sophia University. http://www.jstor.org/ stable/2382774

MORI, Ôgai. Vita sexualis. Tradução Kazuji Ninomiya e Sanford Goldstein. Tóquio: Tuttle, 1972. Kindle, s/d.

16 Akutagawa, Rashômon e outras histórias. Trad. Madalena Hashimoto e Junko Ota. São Paulo: Paulicéia, 1992, p. 143. 
. Ôgai ha koredake yome! 鴎外はこれだけ読め! (Obras Essenciais de Ôgai). Koten kyôyô bunko. Tóquio: Iwanami, 1940. Kindle, 2013.

MURAKAMI, Takayuki. "Lovers in Disguise: A Feature of Romantic Love in Meiji Literature". Comparative Literature Studies, Vol. 28, No. 3, 1991, pp.213-233. Penn State University Press. http://www.jstor.org/stable/40246789.

SAEKI, Junko. "From iro (eros) to ai=love: the case of Tsubouchi Shôyô". Trad. Indra Levy. In LEVY, Indra (ed.). Translation in Modern Japan. Londres e Nova York: Routledge, 2011, pp. 73-101.

VINCENT, Keith J. "Sexuality and Narrative in Sôseki's Kokoro". In CORNYETZ, Nina; KEITH VINCENT, J. (eds.). Perversion and Modern Japan - Psychoanalysis, Literature, Culture. New York: Routledge, 2011.

\section{Obras do escritor traduzidas ao português:}

NATSUME Sôseki. Sonhos de Dez Noites. Tradução Antonio Nojiri. São Paulo: Aliança Cultural Brasil-Japão, 1996.

. Kokoro Coração. Tradução Junko Ota. São Paulo: Globo, 2008.

. Eu Sou um Gato. Tradução Jefferson Jose Teixeira. São Paulo: Estação Liberdade, 2008.

. E Depois. Tradução Lica Hashimoto. São Paulo: Estação Liberdade, 2011.

. Sanshiro. Tradução e notas Fernando Garcia. São Paulo: Estação Liberdade, 2013.

. O Portal. Tradução Fernando Garcia. São Paulo: Estação Liberdade, 2014.

\section{Obras do escritor traduzidas ao inglês:}

. Botchan (Master Darling). Tradução Yasotaro Morri. Kindle, s/d, (ed. 1919).

. Kokoro. Tradução Edwin McClellan. Kindle, s/d (ed. 1957).

. Sanshirô. Tradução e notas Jay Rubin. Introdução Murakami Haruki. Londres: Penguin Books, 2009.

\section{Obras do escritor em japonês:}

. Sôseki wa koredake yome Hachidai kessakushî 漱石はこれだけ読め! 八大傑作 集 (Leitura Essencial: Oito Obras-Primas). Koten kyôyô bunko, Chikuma, 1988. Kindle, 2013.

Natsume Sôseki zenshû 夏目漱石全集 (Obra Completa de Natsume Sôseki). Iwanami, 2002. Kindle, 2013. 